\title{
Association between the heart rate early after heart transplantation and the long term clinical outcomes
}

\author{
Bedanova $\mathrm{H}^{1}$, Fila $\mathrm{P}^{1}$, Horvath $\mathrm{V}^{1}$, Sebo $\mathrm{M}^{1}$, Podrouzkova $\mathrm{H}^{2}$, Orban $\mathrm{M}^{1}$, Nemec $\mathrm{P}^{1}$ \\ Center of Cardiovascular and Transplant Surgery Brno, Brno, Czech Republic. hbedanova@seznam.cz
}

\begin{abstract}
BACKGROUND: A strong correlation between a lower heart rate and survival has been demonstrated in various patient populations. The optimal heart rate for heart transplant patients is still unknown. The aim of our study was to evaluate the association between an early heart rate and survival after heart transplantation.

MATERIAL AND METHODS: We retrospectively analysed a group of 330 patients, who underwent heart transplantation in our institution from 1994 to 2014 and complete datasets, including 24-hour heart rate monitoring one month after the heart transplantation. Patients were divided in 2 groups: Group A $(n=278)$ with the average 24-hour heart rate $<90 \mathrm{bpm}$, and Group B $(n=52)$ with $\geq 90 \mathrm{bpm}$.

RESULTS: The average period of monitoring was $7.5 \pm 5.3$ years. No differences in baseline characteristics were observed in both groups of recipients and respective donors. One-year survival in groups A and B was $92 \%$ and $81 \%$, respectively; 5 -year survival was $79 \%$ and $60 \%$, respectively; and 10 -year survival was 66 $\%$ and $50 \%$, respectively $(p=0.001)$.

CONCLUSION: Increased heart rate in the early post-transplant period was significantly associated with a poorer survival rate in patients after heart transplantation (Tab. 2, Fig. 1, Ref. 25). Text in PDF www.elis.sk. KEY WORDS: heart rate early heart transplantation, long term clinical outcomes.
\end{abstract}

\section{Introduction}

Results of numerous studies suggest that a lower resting heart rate is related to longevity. The slower our heart beats, the better it is for us (1). In the mammals' world, there is a linear relationship between heart rate and length of life. Smaller animals with high heart rate of around 600/min live only a few years while large animals with heart rate of around $10-30 /$ min live 50 years or longer. Humans, however, are an exception as they live much longer than what corresponds to their heart rate.

A higher heart rate is considered a risk factor for developing cardiovascular diseases. Epidemiological studies confirm a higher mortality in various cardiovascular diseases (2), including hypertension (3), acute myocardial infarction (4), in patients with heart failure or left ventricular dysfunction $(5,6)$.

The exact mechanism of negative impact of higher heart rate is not known, but lower sheer stress during higher heart rate is expected to support creation of atherosclerotic plaques by damaging walls of arteries and causing endothelial dysfunction. Other proposed mechanisms included an increased metabolic rate leading to higher oxidative stress, larger oxygen demand, increased

${ }^{1}$ Center of Cardiovascular and Transplant Surgery Brno, Brno, Czech Republic, and ${ }^{2}$ Faculty Hospital Brno, Internal Cardiological Department, Brno, Czech Republic

Address for correspondence: $\mathrm{H}$. Bedanova, MD, Center of Cardiovascular and Transplant Surgery Brno, Pekarska 53, 65691 Brno, Czech Republic. Phone: +420606115949, Fax: +420543182541 arterial stiffness, presenting a burden of higher afterload on left ventricle (7).

The optimal heart rate post heart transplantation (HTx) is debatable. The aim of our study was to determine whether a higher heart rate in the early post-transplant period affects the long-term survival after the heart transplantation.

\section{Materials and methods}

We retrospectively analysed a total of 330 patients, who underwent HTx at our institution between 1993-2014 and for whom we had complete data, including the 24 hours Holter monitoring of heart rate approximately one month after HTx, i.e. before being released home. The average 24-hour heart rate value was used for the analysis. We divided the patients into 2 groups: Group A ( $\mathrm{n}=$ 278 ) with an average heart rate $<90 / \mathrm{min}$, and Group B $(\mathrm{n}=52)$ with a heart rate $\geq 90 / \mathrm{min}$. We chose the cut off value for heart rate as $90 /$ min based on previously published literature $(8,9,10)$. Echocardiography was performed at time of Holter monitoring, ejection fraction was assessed by Simpson's biplane according to the guidelines.

According to our Unit's protocol, all patients were given an induction immunosuppressive treatment with the anti-interleukin-2 receptor monoclonal antibody basiliximab (Simulet, Novartis) followed by a triple therapy consisting of: cyclosporin A (Sandimmunn Neoral, Novartis) or tacrolimus (Prograf, Advagraf, Astellas Pharma), mycophenolate mofetil (Cellcept, Roche) and corticosteroids. Endomyocardial biopsies were performed once a week 
in the first month after HTx, then once a month up to totally ten biopsies during the first year after transplantation.

Histopathologic results were assessed using the Banff classification 1990. Grade 2 and higher were considered as acute cellular rejection.

Survival was investigated based on hospital records.

\section{Statistical analysis}

Basic characteristics of recipients and donors were presented using methods of descriptive analysis. Results are given as the mean with the standard deviation (SD), median, lower quartile (Q1), upper quartile (Q3), minimum and maximum with continuous variables, and using absolute and relative numbers with categorical variables.

Categorical variables were compared using the Fisher's test. As continuous variables did not show a normal distribution pattern, the non-parametric Mann-Whitney was applied to compare inter-group parameters. Comparison of survival between the two groups was calculated using the Kaplan-Mayer survival analysis.

All analyses were conducted at a level of significance of $5 \%$ (i.e., $p$ values $<0.05$ are considered statistically significant), using statistical software Statistica 12, (StatSoft, USA).

\section{Results}

Basic characteristics of patients in both groups are listed in the Table 1. Patients in both groups did not statistically significantly differ by their age, diagnosis, order on the waiting list, and occurrence of acute cellular rejection or length of cold ischemia. Also, characteristics of relevant graft donors were similar in both groups (Tab. 2), however, there were more female gender donors in Group B $(\mathrm{p}=0.04)$. Beta-blockers were given in Group A to 147 patients (53\%), in Group B to 28 patients (54\%). Calcium

Tab. 1. Basic characteristics of recipients.

\begin{tabular}{|c|c|c|c|c|}
\hline Variables & Statistics & $\begin{array}{l}\text { Group A } \\
(\mathrm{n}=278)\end{array}$ & $\begin{array}{c}\text { Group B } \\
(n=52)\end{array}$ & $\mathrm{p}$ \\
\hline Age (years) & $\begin{array}{c}\text { Mean } \pm \text { SD } \\
\text { Median (Q1-Q3) } \\
\text { Min-Max }\end{array}$ & $\begin{array}{c}51.9 \pm 9.5 \\
53.9(47.6-58.9) \\
19.2-66.2\end{array}$ & $\begin{array}{c}50.5 \pm 11.3 \\
54.5(43.0-58.4) \\
20.0-65.4\end{array}$ & 0.582 \\
\hline $\begin{array}{l}\text { Gender } \\
\text { Male } \\
\text { Female } \\
\end{array}$ & $\begin{array}{l}\mathrm{n}(\%) \\
\mathrm{n}(\%)\end{array}$ & $\begin{array}{c}234(84.2 \%) \\
44(15.8 \%)\end{array}$ & $\begin{array}{c}40(76.9 \%) \\
12(23.1 \%)\end{array}$ & 0.227 \\
\hline $\begin{array}{c}\text { Diagnosis: } \\
\text { DCMP }^{\mathrm{a}} \\
\text { CAD }^{\mathrm{b}} \\
\text { Others } \\
\end{array}$ & $\begin{array}{l}\mathrm{n}(\%) \\
\mathrm{n}(\%) \\
\mathrm{n}(\%)\end{array}$ & $\begin{array}{c}133(47.8 \%) \\
114(41.0 \%) \\
31(11.2 \%)\end{array}$ & $\begin{array}{c}21(40.4 \%) \\
26(50.0 \%) \\
5(9.6 \%) \\
\end{array}$ & 0.516 \\
\hline $\begin{array}{l}\mathrm{WL}^{\mathrm{c}} \\
\text { Urgent } \\
\text { Normal } \\
\end{array}$ & $\begin{array}{l}\mathrm{n}(\%) \\
\mathrm{n}(\%)\end{array}$ & $\begin{array}{l}153(55.0 \%) \\
125(45.0 \%)\end{array}$ & $\begin{array}{l}28(53.9 \%) \\
24(46.1 \%)\end{array}$ & 0.881 \\
\hline $\begin{array}{l}\mathrm{AR}^{\mathrm{d}} \\
\text { Yes } \\
\text { No } \\
\end{array}$ & $\begin{array}{l}\mathrm{n}(\%) \\
\mathrm{n}(\%)\end{array}$ & $\begin{array}{l}109(39.2 \%) \\
153(60.8 \%)\end{array}$ & $\begin{array}{l}26(50.0 \%) \\
26(50.0 \%)\end{array}$ & 0.167 \\
\hline BMI $\left(\mathrm{kg} / \mathrm{m}^{2}\right)^{\mathrm{e}}$ & $\begin{array}{c}\text { Mean } \pm \text { SD } \\
\text { Median (Q1-Q3) } \\
\text { Min-Max }\end{array}$ & $\begin{array}{c}25.8 \pm 3.5 \\
26.0(23.2-28.4) \\
16.7-35.2 \\
\end{array}$ & $\begin{array}{c}25.0 \pm 3.8 \\
24.8(22.6-27.9) \\
16.1-33.2 \\
\end{array}$ & 0.173 \\
\hline
\end{tabular}

Tab. 2. Basic characteristics of donors.

\begin{tabular}{|c|c|c|c|c|}
\hline Variables & Statistics & $\begin{array}{l}\text { Group A } \\
(\mathrm{n}=278)\end{array}$ & $\begin{array}{l}\text { Group B } \\
(\mathrm{n}=52)\end{array}$ & $\mathrm{p}$ \\
\hline \multirow[t]{3}{*}{ Age (years) } & Mean \pm SD & $36.0 \pm 12.7$ & $32.5 \pm 12.9$ & \multirow{3}{*}{0.064} \\
\hline & Median (Q1-Q3) & $36.0(25.0-47.0)$ & $29.5(22.0-43.5)$ & \\
\hline & Min-Max & $11.0-61.0$ & $15.0-57.0$ & \\
\hline \multicolumn{5}{|l|}{ Gender } \\
\hline Male & $\mathrm{n}(\%)$ & $237(85.3 \%)$ & $38(73.1 \%)$ & \multirow{2}{*}{0.041} \\
\hline Female & $\mathrm{n}(\%)$ & $41(14.7 \%)$ & $14(26.9 \%)$ & \\
\hline \multicolumn{5}{|l|}{ Cause of death: } \\
\hline Craniotrauma & $\mathrm{n}(\%)$ & $158(56.8 \%)$ & $30(57.7 \%)$ & \multirow{3}{*}{0.516} \\
\hline $\mathrm{SAH}^{\mathrm{a}}$ & $\mathrm{n}(\%)$ & $86(30.9 \%)$ & $18(34.6 \%)$ & \\
\hline Others & $\mathrm{n}(\%)$ & $34(12.3 \%)$ & $4(7.7 \%)$ & \\
\hline \multirow{3}{*}{ BMI $\left(\mathrm{kg} / \mathrm{m}^{2}\right)^{\mathrm{b}}$} & Mean \pm SD & $24.7 \pm 3.0$ & $23.9 \pm 3.5$ & \multirow{3}{*}{0.089} \\
\hline & Median (Q1-Q3) & $24.5(22.9-26.3)$ & $23.9(21.3-26.2)$ & \\
\hline & Min-Max & $16.1-36.6$ & $16.7-32.3$ & \\
\hline \multirow{3}{*}{$\operatorname{CIT}(\min )^{\mathrm{c}}$} & Mean \pm SD & $161.5 \pm 53.7$ & $152.3 \pm 57.4$ & \multirow{3}{*}{0.254} \\
\hline & Median (Q1-Q3) & $166.5(115-202)$ & $159.5(95-196)$ & \\
\hline & Min-Max & $60.0-277.0$ & $66.0-260.0$ & \\
\hline
\end{tabular}

${ }^{\mathrm{a}}$ subarachnoid hemorrhagie, ${ }^{\mathrm{b} B o d y}$ Mass Index, ${ }^{\mathrm{c}}$ cold ischemia time

channel blockers were given to 71 patients $(25 \%)$ in Group A and to 9 patients $(17 \%)$ in Group B. The difference between the two groups was not statistically significant $(p=1.00$ and 0.223$)$.

There was no statistically significant difference between the Groups A and B in left ventricular ejection fraction (61 $\pm 5.7 \%$ and $62 \pm 5.9 \% ; p=0.615)$, creatinine levels $(108 \pm 49$ and $107 \pm$ $35 ; \mathrm{p}=0.881)$, number of patients with diabetes mellitus $(47 \%$ and $38 \%, p=0.289)$, hypertension ( $49 \%$ and $48 \%, p=0.668)$, and number of patients requiring haemodialysis early after HTx (16\% and $23 \%, \mathrm{p}=0.149$ ).

The survival rate at years 1,5 and 10 respectively were as follows: Group A (92 \%, $79 \%$ and $66 \%$ ), Group B (81\%, $60 \%$ and $50 \%$ ). The difference was statistically significant $(\mathrm{p}=0.001)$ (Fig. 1).

\section{Discussion}

Although survival of patients after HTx nowadays has greatly improved, the latest data in the register of the International Society for Heart and Lung Transplantation (ISHLT) shows the 1 year survival rate in about $90 \%, 5$ years in about $70 \%$, but only about

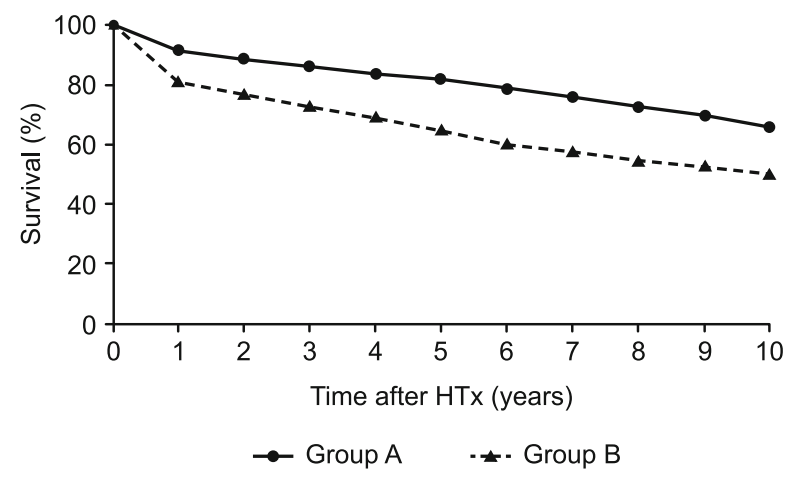

Fig. 1. Kaplan-Meier curves of survival in both groups. 
$20 \%$ of patients survive 20 years or longer (11). Therefore, there is still much to improve in this area and, if there are any ways to achieve better long-term survival rate, they should be applied. According to our results, patients with the heart rate below $90 / \mathrm{min}$ had better long-term survival. Sinus tachycardia is the most common arrhythmia after HTx. As the result of the parasympathetic denervation, transplanted hearts lose the vagal influence on the sinoatrial node, which leads to an increased resting heart rate (12) and loss of the circadian variation, which is very low in patients after HTx (13). In the early post-transplant period, the donor's heart manifests metronome-like chronotropic behaviour (14).

Our findings are supported also by literature data of other authors, although presented on significantly smaller series of patients. Anand (9) showed on a set of 78 patients that patients with resting heart rate higher than 90/min after 3 months from transplantation are 2.8 times more likely to die than those with the heart rate $90 / \mathrm{min}$ or lower. The same conclusion was reached by Ferrer et al (15), who demonstrated on a set of 191 patients that resting heart rate of $100 / \mathrm{min}$ and above is an independent risk factor for mortality. Higher heart rate presents the risk also in a longer period from transplantation. Castel (10) confirmed on a set of 312 patients, a higher mortality among those, whose heart rate one year after transplantation was $90 / \mathrm{min}$ or higher. In all these studies, tachycardia was associated with a higher all-cause mortality rate.

Higher heart rate is demonstrably a risk factor for cardiovascular diseases, including coronary artery disease (CAD) $(16,17)$, the question is whether tachycardia post HTx increases also the risk of graft vasculopathy (CAV). Findings by Ambrosi et al (18) in 143 patients refuted this hypothesis. The same conclusion was reached by Olmetti (8) in a series of 244 patients, where he determined on denervated hearts that sinus tachycardia is not a risk factor for development of coronary atherosclerosis. Using intravascular ultrasound examination of coronary arteries (IVUS) on 130 patients after HTx, Gullestad (19) demonstrated an even higher prevalence of CAV in patients with lower heart rate. These authors explain their findings by the fact that CAV by itself may be the cause of dysfunction of the sinus node, and lower heart rate is a consequence of CAV rather than its cause. These data show that what is true for coronary atherosclerosis in the common population, might not be for vasculopathy post HTx.

Although a higher heart rate probably does not affect the incidence and progression of graft vasculopathy, it still has a negative impact on long-term survival. Therefore, more aggressive treatment of tachycardia in patients after HTx would be, according to our results, very well founded. There are several options: digitalis, beta-blockers (BB), calcium channel antagonists and If cannel antagonists. Beta-blockers have not been favoured in the post heart transplant population, although they remain a main part of the treatment in patients with heart failure.

According to an earlier study from Verani (20), BB lowered the heart rate of patients but, at the same time, decreased their cardiac output by up to $42 \%$. Although we treated the same percentage of patients in both groups with BB, i.e. $53 \%$ and $54 \%$, the heart rate of patients in group B remained 90 beats/min and above.
Calcium channel antagonists are commonly used after HTx to treat hypertension. There is only very little information available about their use to slow down the heart rate. Schulmann (21) investigated the effect of verapamil on a denervated heart and found, in addition to a negative chronotropic effect, also a considerable negative inotropic effect. In our patients, $\mathrm{Ca}$ antagonists were given along with cyclosporin at the beginning of the monitoring period. It is advocated that, this increases the cyclosporin levels (22) therefore allowing us to cut down on the dose thus minimising its side effect without adversely affecting the immunosuppressive effect.

The more promising in terms of slowing down the heart rate seems to be $I_{f}$ channel antagonists, specifically ivabradine. It has a very good bradycardial effect, without any negative inotropic or antihypertensive effect. Doesch (23) compared the effects of BB and ivabradine on a set of 25 patients after HTx. He found that ivabradine decreased heart rate with the same efficacy and, moreover, it was better tolerated than BB. The same author demonstrated that, in addition to the bradycardiac effect of ivabradine, a change to a significant reduction of the left ventricular mass during 36 months of monitoring 27 HTx patients (24). Zhang (25) also concluded the effectiveness of ivabradine on heart rate reduction in HTx patients, without any negative impact on myocardial contractility, blood pressure and the conducting system. None of the patients in our series were treated with ivabradine, however, it is now given to most patients in our institution in the light of current research findings and the better survival rate demonstrated in the low heart rate group of our study.

The strength of our study lies in the relatively large number of patient data analysed and the fact that all patients underwent a 24-hour heart rate monitoring. This study, however, was limited by the retrospective nature of its design and the lack an in-depth analysis of the cause of death as this was not always known. Besides, coronary angiography was not available for most patients, especially at the beginning of the monitoring period, and only a small number of the patients was subjected to intravascular ultrasound examination, which was provided only in the last 5 years. This study is to be interpreted within its context. It is an observational study and thus cannot explain pathophysiology mechanisms or reveal causal relationships.

\section{Conclusion}

An increased heart rate in the early post-transplant period was significantly associated with worse survival in patients after heart transplantation. Female gender of donor in this context also appears to be a risk factor. According to our results, more aggressive approach in the treatment of tachycardia should be beneficial for the patients after heart transplantation.

\section{References}

1. Cooney MT, Vartiainen E, Laatikainen T, Juolevi A, Dudina A, Graham IM. Elevated resting heart rate is an independent risk factor for cardiovascular disease in healthy men and women. Am Heart J 2010; 159 (4): 612-619. 
2. Böhm M, Reil JC, Deedwania P, Kim JB, Borer JS. Resting heart rate: risk indicator and emerging risk factor in cardiovascular disease. Am J Med 2015; 128 (3): 219-228.

3. Palatini P, Jilius S. Elevated heart rate a major risk factor for cardiovascular disease. Clin Exp Hypertens 2004; 26: 637-644.

4. Jensen MT, Kaiser C, Sandsten KE, Alber H, Wanitschek M, Iversen A et al. Heart rate at discharge and long-term prognosis following percutaneous coronary intervention in stable and acute coronary syndromes - results from the BASKET PROVE trial. Int J Cardiol 2013; 168 (4): 3802-3806.

5. Castagno D, Skali H, Takeuchi M, Swedberg K, Yusuf S, Granger CB et al. Association of heart rate and outcomes in a broad spectrum of patients with chronic heart failure: results from the CHARM (Candesartan in Heart Failure: Assessment of Reduction in Mortality and morbidity) program. J Am Coll Cardiol 2012; 59 (20): 1785-1795.

6. Ford I, Robertson M, Komajda M, Böhm M, Borer JS, Tavazzi L et al. Top ten risk factors for morbidity and mortality in patients with chronic systolic heart failure and elevated heart rate: The SHIFT Risk Model. Int J Cardiol 2015; 184: 163-169.

7. Critchley WR, Yonan N, Shaw SM, Fildes JE. Heart Rate After Cardiac Transplantation-Lessons From the Tortoise and the Shrew. Transplant J 2013; 95: 259-265.

8. Olmetti F, Pinna GD, Meastri R, D’Armini A, Pellegrini C, Viganò $\mathbf{M}$ et al. Heart rate and cardiac allograft vasculopathy in heart transplant recipients. J Heart Lung Transplant 2011; 30: 1368-1373.

9. Anand RG, Reddy MT, Yau CL, Myers L, Amin RR, Stahls PF et al. Usefulness of heart rate as an independent predictor of survival after heart transplantation. Am J Cardiol 2009; 103 (9): 190-194.

10. Castel MÁ, Roig E, Rios J, Tomas C, Mirabet S, Cardona M et al. Long-term prognostic value of elevated heart rate one year after heart transplantation. Int J Cardiol 2013; 168 (3): 2003-2007.

11. Lund LH, Edwards LB, Kucheryavaya AY, Benden C, Christie JD, Dipchand AI et al. The registry of the International Society for Heart and Lung Transplantation: thirty-first official adult heart transplant report - 2014; focus theme: retransplantation. J Heart Lung Transplant 2014; 33 (10): 996-1008.

12. Stecker EC, Strelich KR, Chugh SS, Crispell K, McAnulty JH. Arrhytmias after orthotopic heart transplantation. J Card Fail 2005; 11 : 454-472.

13. Arrowood A, Minisi AJ, Goudreau E, Davis AB, King AL. Absence of parasympathetic control of heart rate after human orthotopic cardiac transplantation. Circulation 1997; 96: 3492-3498.
14. Kresh JY, Izrailtyan I. Evolution in functional complexity of heart rate dynamics: a measure of cardiac allograft adaptability. Am J Physiol 1998; 275 (3): 720-727.

15. Melero-Ferrer JL, Sánchez-Lázaro IJ, Almenar-Bonet L, Martínez-Dolz L, Buendía-Fuentes F, Portolés-Sanz M et al. Impact of basal heart rate on long-term prognosis of heart transplant patients. Transpl Int 2013; 26 (5): 502-507.

16. Fox K, Borer FS, Camm AJ, Danchin N, Ferrari R, Lopez Sendon JL, Steg PG et al. Resting heart rate in cardiovascular disease. J Am Coll Cardiol 2007; 50: 823-830.

17. Vitale C, Iellamo F, Volterrani M, Lombardi M, Fini M, Banach M et al. Heart rate control in an unselected consecutive population of outpatients with stable coronary artery disease: analysis of the CARDIf study cohort. Angiology 2010; 61 (8): 763-767.

18. Ambrosi P, Kreitmann B, Habib G. Does heart rate predict allograft vasculopathy in earttransplant recipients? Int J Cardiol 2010; 145: 256-257.

19. Gullestad I, Ross H, Myers J, Hoang K, Hunt S, Stinson EB et al. Importance of decreased heart rate in predicting transplant coronary artery disease. Clin Transplant 197; 11: 628-632.

20. Verani MS, Nishimura S, Mahmarian JJ, Hays JT, Young JB. Cardiac function after orthotopic heart transplantation: response to postural changes, exercise, and beta-adrenergic blockade. J Heart Lung Transplant 1994; 13 (2): 181-193.

21. Schulman DS, Herman BA, Edwards T, Ziady G, Uretsky BF. Effect on verapamil on ventricular function: studies in denervated human heart. J Cardiovasc Pharmacol 1993; 21 (4): 567-572.

22. Tesi RJ, Hong J, Butt KM, Jaffe BM, McMillen MA. In vivo potentiation of cyclosporine immunosuppression by calcium antagonists. Transplant Proc 1987; 19: 1382-1384.

23. Doesch AO, Celik S, Ehlermann P, Frankenstein L, Zehelein J, Koch A et al. Heart rate reduction after heart transplantation with betablocker versus the selective If channel antagonist ivabradine. Transplantation 2007; 84 (8): 988-996.

24. Doesch AO, Mueller S, Erbel C, Gleissner CA, Frankenstein L, Hardt $S$ et al. Heart rate reduction for 36 months with ivabradine reduces left ventricular mass in cardiac allograft recipients: a long-term follow-up study. Drug Des Devel Ther 2013 (5); 7: 1323-1328.

25. Zhang R, Bobylev D, Stiefel P, Haverich A, Bara C. Lasting reduction of heart transplant tachycardia with ivabradine is effective and well tolerated: results of 48-month study. Clin Res Cardiol 2012; 101 (8): 631-636.

Received January 28, 2017. Accepted February 21, 2017. 